Originalartikkel

\title{
Korleis møter allmennlegane pasientanes livsproblem?
}

\author{
Samandrag \\ Bakgrunn. Mange problem i allmenn- \\ medisinen vert presenterte som livs- \\ problem, og diskrepansen mellom \\ tradisjonelle medisinske problem \\ og livsproblema til pasientane kan vere \\ frustrerande for allmennlegen.
}

\begin{abstract}
Materiale og metode. Artikkelen byggjer på semistrukturerte djupintervju via e-post med seks allmennlegar. Intervjua blei analysert med samtaleanalytiske metodar med kartlegging av kva rolle legane meinte dei hadde, om dei oppfatta seg sjølve som terapeutar og korleis dei opplevde den personlege belastninga det er å jobbe innan allmennmedisinen.
\end{abstract}

Resultat. Dei fleste skilde ikkje skarpt mellom medisinske og ikkje-medisinske problem. Dei definerte likevel implisitt medisinske problem nokså snevert som somatiske problem, og oppfatta seg først og fremst som ekspertar på det området. Dei beskreiv seg sjølve i ei terapeutrolle meir i retning prest enn psykoterapeut. Enkelte meinte at praksis hadde gjort dei til tryggare og meir tolerante menneske. Men det var også mange utsegner om at dei kjende seg hjelpelause som legar.

Fortolking. Allmennlegane er legar for heile folket. Dei må ta omsyn til både friske og sjuke med ulike livsog helseproblem, og opplever ofte at det er diskrepans mellom den faglege kompetansen dei har og dei utfordringane dei møter.

\author{
John Nessa \\ john.nessa@isf.uib.no \\ Edvin Schei \\ Per Stensland \\ Seksjon for allmennmedisin \\ Institutt for samfunnsmedisinske fag \\ Universitetet i Bergen \\ Kalfarveien 31 \\ 5018 Bergen
}

Eit av særtrekka i allmennmedisinen er at det er pasienten i større grad enn sjukdommen eller organsystemet som står i sentrum i det kliniske arbeidet (1). Mens ein i lærebøker i andre kliniske fag gjerne definerer faget som eit sett sjukdommar og kliniske tilstandar, definerer standardverk i allmennmedisin faget som eit sett roller eller funksjonar allmennlegen har andsynes pasienten og samfunnet $(2,3)$. Mange tilstandar i allmennmedisinen vert presenterte $\mathrm{i}$ form av livsproblem som direkte eller indirekte påverkar helse og sjukdom. Den medisinske profesjonen har ikkje eit eintydig svar på korleis ein skal møte dei ulike livsproblema pasientane presenterer, og diskrepansen mellom det som vanlegvis er rekna som medisinske problem og det som plagar den enkelte pasient kan opplevast som frustrerande for allmennlegen.

I denne artikkelen vil vi belyse korleis allmennlegane møter dei livsproblema som pasientane kjem fram med i konsultasjonen. Vi vil både undersøke korleis legane personleg opplever å møte slike problem og kva rolle dei meiner dei har, og bør ha, for å kunne hjelpe pasienten.

\section{Materiale og metode}

Undersøkinga er gjennomført av forfattarane i fellesskap. Kvar forfattar har intervjua to legar - til saman seks, tre kvinner og tre menn. Intervjua er gjort via e-post over ein periode på fleire månader. Frå ei liste over praksislærarar ved Universitetet i Bergen gjorde vi eit strategisk utval blant allmennlegar som ikkje hadde akademiske stillingar eller var leiarar i faglege organisasjonar (4). Dei som blei intervjua, rekna vi som engasjerte og reflekterte kollegaer. Både praksis frå større byar og typiske distriktskommunar var representerte. Fem av dei seks var spesialistar i allmennmedisin, den sjette var ein relativt nyutdanna lege.

Dei hovudspørsmåla vi stilte, utvikla vi i fellesskap ved å utforme ein forskingsprotokoll der vi utveksla idear og stikkord som vi meinte burde inkluderast $\mathrm{i}$ intervjuguiden ut frå eigne erfaringar frå allmennmedisin og litteratur om lege-pasient-relasjonen (ramme 1). Vi følgde ein semistrukturert intervjuguide med både hovudspørsmål og individuelt tilpassa oppfølgingsspørsmål for kvar e-postsending. Eit stykke på veg instruerte vi også legane i korleis de skulle svare. Dei blei oppmoda til å tenke og assosiere fritt og svare spontant utan tanke på kva som var «rett» eller forventa svar, og utan å bry seg med om dei kanskje motsa seg sjølve i dei ulike svara dei kom med. Det var ingen tidsfrist for svar, men gjekk det urimeleg lang tid, purra vi på deltakarane.

Heile materialet er analysert etter prinsippet for systematisk tekstkondensering og ved samtaleanalyse $(5,6)$. Kvar for oss gjennomførte vi analysane våre av heile materialet ved hjelp av ein av desse metodane. Så sluttførte vi analysane i fellesskap. På denne måten oppnådde vi ein metodetriangulering der fortolkingane kompletterte og justerte kvarandre. Denne artikkelen byggjer på det vi fann ut frå samtaleanalyse (6-8). Kvart intervju er blitt lest som ein samanhengande, heilskapleg tekst. Enkeltutsegner blir tolka i lys av samanhengen og intervjuet redigert sekvensielt - relevante tekstavsnitt blir plassert i kronologisk rekkefølgje med underoverskrifter som tematisk dekkjer dei emneområda intervjuet dreier seg om.

Vi valde «rolleforståing» og «personleg slitasje» som underoverskrifter. Omgrepet «rolle» bruker vi i tråd med distinksjonen mellom statusrolle og aktivitetsrolle som Markovà og medarbeidarar har definert (9). «Statusrolle» betyr kva posisjon ein har i eit sosialt fellesskap, «aktivitetsrolle» handlar om kva ein kan og bør gjere i dette fellesskapet. Det er den sistnemnde vi har sett på her. Legane uttrykker til dømes tvil omkring

\section{Hovudbodskap}

- Det er vanskeleg å skilje mellom medisinske og ikkje-medisinske problem i allmennmedisinsk praksis

- Allmennlegane meiner dei har ein viktig terapeutisk funksjon, men finn det ikkje naturleg å beskrive dette som psykoterapi

- Kombinasjonen av sterke krav til seg sjølv, fagleg hjelpeløyse og uklare og høge forventningar gir stor slitasje for allmennlegane 


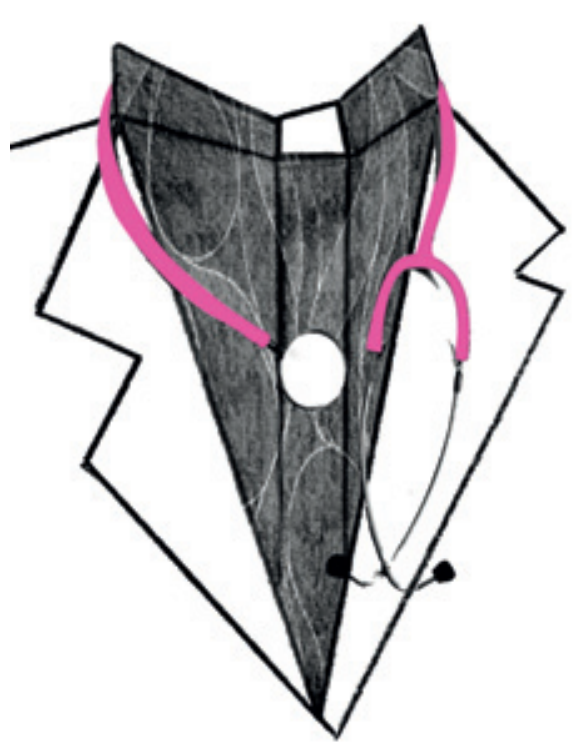

Prest eller psykoterapeut eller...? Illustrasjon Anne Gitte Hertzberg

spørsmålet om dei driv psykoterapi eller ei. Det er ein tvil om aktivitetsrolla. Dei er derimot ikkje i tvil om statusrolla som allmennlege.

Resultata frå studien er illustrert med ordrette sitat frå e-postane, utan omsyn til rettskriving eller språkform.

\section{Resultat}

Medisinske og «andre» problem

To av legane svarte at dei skilde klart mellom medisinske problem og andre problem. Tre andre var like klare på at dei i praksis ikkje skilde. Ein av deltakarane oppdaga etter kvart som ho tenkte på problemstillinga at ho hadde endra syn. Grunnen var både at eit slikt skilje kunne tilsløre medisinske problem - «har oversett somatisk sjukdom fordi eg har definert problem som ikkje-medisinske» - og at skiljet ikkje var føremålstenleg på generelt grunnlag - «etter kvart som eg tenkjer på dette, blir det meir og meir klart for meg at skiljet i praksis er minimalt».

Dei som ikkje skilde mellom medisinske

\section{Ramme 1}

\section{Dei fire hovudspørsmåla}

Skil du mellom medisinske problem og «andre problem» i din praksis?

Synest du at du har makt til å verke byggjande, lækjande, styrkande, klargjerande i livet til pasientane?

Er det personlegdomstrekk ved deg sjølv som er blitt tydelegare og sterkare gjennom dine år som lege og som du knyter til praksiserfaringa?

Er det noko som gjer at du iblant kjenner deg hjelpelaus som lege? og ikkje-medisinske problem, grunngav sitt syn litt forskjellig. Ein deltakar meinte at å skilje kunne vere ein etisk tvilsam måte å avvise pasientar på: «I drøftingen av medisinsk/ikke-medisinsk legger vi nok også andre valører: Verdig/ikke-verdig legens tid, verdig/ikke-verdig sykemelding og trygdeytelser. Pasientprestisje og legeprestisje.»

Ein annan poengterte at skiljet var irrelevant fordi ein måtte ha eit konsultasjonssvar anten problemet var strengt medisinsk eller ikkje. Den tredje deltakaren meinte det var «håplaust å skulle behandle berre dei «medisinske» problema. Dei som kjem til oss, eller i alle fall meg, opplever eg bed om noko meir».

Det kan verke som om alle saman definerte medisinske problem nokså snevert somatisk, eventuelt spedd med alvorleg psykisk sjukdom: «Samlivsvansker/reaktiv depresjon er ikke-medisinsk. Hverdagspsykiatri, en del av livet, således ikke-medisinsk.»

Det verka også som om alle informantane skilde mellom rolla som «ekspert» i medisinske spørsmål og rolla som «samtalepartnar» når problemet ikkje var medisinsk.

\section{Terapeutisk rolle}

Alle deltakarane la vekt på kva problem pasienten kom med og kva slags hjelp dei forventa å få av legen. Ein kommenterte at allmennlegen representerte eit lågterskeltilbod som er mindre stigmatiserande enn psykolog og sosialkontor. Ein annan minte om at vi blir vist stor tillit av pasientane når dei kjem med sine livsproblem. Ho meinte at det $\mathrm{i}$ vårt samfunn ikkje var så lett å finne andre som kunne ta den rolla og etterlyste undervisning om dette: «Bør inn i studentundervisninga at livsproblem også er medisinsk arbeid.» Bestillingane frå pasientane kunne sprike $\mathrm{i}$ alle retningar: «Noen forventer å bruke meg som terapeut. Noen vil bare sykemeldes. Noen vil bare ha benzoene sine. Noen vil innlegges hele tiden. Noen vil til psykolog. Noen vil ha henvisning til naturmedisiner fordi de har legeskrekk.»

Alle informantane meinte at samtalen med pasienten hadde sjølvstendig verdi som medisinsk arbeid. Det vanlegaste omgrepet for denne samtalen var «støttesamtale». Andre omgrep som blei brukt var «kvalifisert samtale», «den allmennmedisinske samtale» og «terapeutisk medisinsk samtale». Ein informant var medviten om sjelesorgrolla: «Kanskje det var prest eg skulle ha vore?»

Ingen ville reservasjonslaust kalle dei samtalane dei hadde med pasientane for psykoterapi. Likevel var alle medvitne om at dei i støttesamtalane utførte eit profesjonelt terapeutisk arbeid: «Eg har nok vore terapeut for mange. Når håpløysa er verst, kjenner eg meg tryggast i rolla som lege.» «Driver her-og-nå rettet terapi. Pumper de litt opp. Jeg stusser av og til over hvor stor samtalens makt er, og om det hele er innbilning.»»

\section{Endra personlegdomstrekk}

Det var relativt færre kommentarar om eigen personlegdom og relativt fleire om personleg slitasje. På spørsmål om praksiserfaring hadde gjort personlegdomstrekk tydelegare, svarte dei fleste informantane at det hadde skjedd ein positiv endring: «Praksis har vært med på å modellere viktige sider ved min person og min personlighet.» Gjennom praksis hadde dei vorte tryggare menneske med større sjølvtillit. Ein deltakar hadde utvikla ein toleranse for andre som han sjølv opplevde som mest ufatteleg. Ein annan problematiserte legens personlegdom: «Personlighet har en del å si - grunnen til at leger har $ø$ kt risiko for depresjon og selmord.»

\section{Hjelpelaus som lege?}

Dei fleste deltakarane vedgjekk at dei kjende seg hjelpelause i mange situasjonar. Mange faktorar kunne bidra til det: «Når jeg møter egne tap. Når jeg er pressa selv. Når pasienten er personlighetsforstyrra. På grunn av tids- og kunnskapsmangel.»

Ein fortalde at mange av hennar pasientar hadde tatt livet av seg, og at det då var naturleg for henne å gruble over om ho hadde handla feil som lege. Ein annan opplevde mange urimelege forventningar, og syntest det var fælt når ho ikkje kunne hjelpe folk: «Plasserer ansvaret på meg selv og diverse system, som kommunen og staten.»

Mange kommenterte at legane hadde internalisert høge krav til seg sjølve og til yrkesutøvinga: «Mange vil strekke seg fryktelig langt for å gjøre det beste for andre - og for å være dyktig.» Fleire var inne på at ein kunne risikere å bli utbrent: «Det at vi brenn for noko, er vår største risikofaktor. At vi bryr oss om andre.»

Ein lege trudde ikkje på tradisjonell utbrenningsprofylakse, så som vern av fritid, eit breitt nettverk, hobbyar. Ein annan påpeika samanhengen mellom fagleg hjelpeløyse og personleg slitasje: «Hjelpeløs med eksistensielle problemer som jeg selv kjenner på kroppen.»

Fleire uttrykte at kombinasjonen av sterke krav til seg sjølv og høge forventningar frå andre kunne gje urimelege belastningar. Ein deltakar erkjente at ho hadde måtta løyse dette dilemmaet med sjukemelding: «Går til psykolog. Sykemeldt akkurat nå. Synes det er litt tidlig.»

\section{Diskusjon}

Intervjumetoden vi har brukt, er i tråd med vanlege semistrukturerte djupintervju (10). Denne metoden lèt seg like lett tilpasse e-postforma som munnlege intervju. Ulempa er at ein går glipp av den ikkje-verbale kommunikasjonen. Det spontane vil dessutan falle meir bort og intervjuet få eit meir formelt preg. Gjennom vårt strategiske utval og måten å spørje på har vi identifisert deler av den tause kunnskapen som erfarne klinikarar gjerne representerer (11). Samla sett representerer dei ein betydeleg praksiserfaring. Ved å invitere til 
å tenkje fritt, ustrukturert og «usensurert» meiner vi at vi får fram nyansar i haldningar og synspunkt som er av verdi for faget generelt og som vi vanskeleg kan få fram på anna vis.

Allmennmedisinen er medisinens grenseflate mot samfunnet. Det er og bør vere låg terskel hos fastlegen. Som portvakt inn til andrelinjetenesta må allmennlegen skilje mellom kva som er eit legitimt medisinsk problem og kva som ikkje er det og bestemme på kva nivå pasienten skal få hjelp. Han eller ho må gjere dette under krysspress - på den eine sida respekt for kva pasienten ønskjer og dei formelle rettane han har og på den andre unngå å medikalisere livsproblem unødig.

Frå den medisinske kulturen har legane ei nokså rigid forståing av kva som er eit relevant medisinsk problem. Denne forståinga blir dei fleste legar nøydde til å justere $\mathrm{i}$ møtet med den enkelte pasienten. Vi får inntrykk av at kvar enkelt lege finn eit svar for seg sjølv som fungerer i klinisk praksis, sjølv om svaret både kan variere over tid og ikkje alltid er logisk konsistent. Svara indikerer at denne justeringa av legerolla i møtet med pasientane vert oppfatta som krevjande, ikkje minst tidleg i yrkeslivet.

Det er naturleg å skilje mellom medisinske og ikkje-medisinske problem. I ein kultur der forventningane til helsevesenet stadig aukar og der forståinga av kva som er eit medisinsk problem stadig endrar seg, blir kvar enkelt allmennlege ståande nokså åleine med desse vurderingane. Enkelte åtvarar mot omsorgsfull godleik (12), samstundes som legane blir skulda for ikkje å ta pasientane på alvor. Mange åtvarar mot medikalisering av livsproblem, mens andre hevdar at motstandarane av medikalisering baserer seg på ein for overflatisk, slagordprega og svak teoretisk basis som ikkje har røter i røynda (13). Dei svara våre informantar gir, viser at det ikkje finst ein enkel og standardisert måte å skilje mellom medisinske og ikkje-medisinske problem på dette er i stor grad avhengig av personlege preferansar, arbeidsform og skjønn.

Informantane våre har også mange og divergerande rolleforventningar til seg sjølve som terapeutar. Dei er medvitne om at samtalen har ein sjølvstendig terapeutisk funksjon. Alle deltakarane ser ut til å setje pris på å bli brukt som terapeut, men dei ser ulikt på sin eigen kompetanse på dette området. Jørgen Strøbech påpeikar at det å erkjenne at ein sjølv som lege er den som lækjer via ein terapeutisk prosess, er eit brot med naturvitskapleg tenking og ein overgang til ein humanvitskapleg tenkemåte som legane i utgangspunktet ikkje har utdanning i (14).

Psykoterapiforskinga har vist at hovudeffekten av psykoterapi ikkje primært er ein funksjon av terapeutisk metode (15), men av dei generelle terapifaktorane som er knytt til terapeuten som person, pasienten som person og relasjonen dei imellom (16). Den bri- tiske psykoanalytikaren Michael Balint peika på same poenget ved å understreke verdien av lege-pasient-forholdet og ved å omtale legen som «drug doctor» (17). Allmennlegen har gode vilkår for å ta dei generelle terapifaktorane i bruk, og bør ikkje undervurdere det terapeutiske potensialet som finst i vanleg fastlegepraksis. Legar har potensielt stor symbolsk makt og bør heller ikkje undervurdere si eiga terapeutiske rolle. For gjer dei det, kan dei komme i skade for å unnlate å hjelpe pasienten sjølv om dei er i posisjon til å gjere det (18). Det er behov for å tenke gjennom kva det vil seie å «doktorere», kva det vil seie å ta regien og bruke den legitime profesjonsmakta som ligg i å representere den medisinske institusjonen for å hjelpe folk med dei problema dei har (19). Vi meiner at studien antyder eit behov for å tematisere og standardisere fastlegens terapeutiske rolle (20).

Det ligg i allmennmedisinens arbeidsform og natur at fastlegen på godt og vondt er nøydd til å eksponere seg personleg for pasienten. Dette har først og fremst positive sider. Men legane som yrkesgruppe står i konstant risiko for å slite seg ut. Legane er blitt omtala som ei gruppe med personlegdomstrekk dominert av den såkalla kompulsive triade: tvil, skuldkjensle og overdriven ansvarskjensle (21). Vetlesen argumenterer for at legen i møtet med pasienten verken kan eller bør prøve å skjule at han er sårbar, men oppfatte det som ein ressurs (22). Smith argumenterer for det same (23). Aasland ønskjer legen velkommen ned frå pidestallen og tilbyr i staden ein skammel med fire bein: medisinsk kunnskap og kompetanse, sjølvstende og integritet, samfunnsansvar og samarbeidsevne samt ein høg etisk standard (24). Han føreslår ei omfattande mentor- og karriererådgjeving for alle. Vi støttar det forslaget og vil understreke at det bør vere ein ambisjon - gjennom eit fagleg forsvarleg rammeverk og tett rettleiing - å hjelpe legane med denne utfordringa, slik at dei slepp å løyse problemet på eiga hand gjennom å sjukemelde seg og søkje psykologhjelp.

\section{Oppgitte interessekonflikter: Ingen}

\section{Litteratur}

1. Cassell EJ. Doctoring. The nature of primary care medicine. New York: Oxford University Press, 1997.

2. Hunskår S, red. Allmennmedisin. Oslo: Gyldendal, 2003.

3. Heath I. The mystery of general practice. I: Heath I, red. Matters of life and death. Key writings. Oxon: Radcliffe, 2008: 89-126

4. Stubbs M. Discourse analysis. Oxford: Blackwell, 1983

5. Malterud K. Kvalitative metoder i medisinsk forskning. Oslo: Universitetsforlaget, 2003.

6. Jørgensen MW, Phillips L. Diskursanalyse som teori og metode. Frederiksberg: Roskilde Universitetsforlag, 1999

7. Flick U. An introduction to qualitative research. London: Sage Publications, 2005: 196-211.

8. Willig C. Discourse analysis. I: Smith JA, red. Qualitative psychology. A practical guide to research methods. London: Sage Publications, 2008: $160-85$
9. Markovà I, Linell P Grossen M et al. Dialogue in focus groups. London: David Brown Book Co, 2007. 10. Kvale S. InterViews. An introduction to qualitative research interviewing. London: Sage Publications, 1996

11. Malterud K. The art and science of clinical knowledge: evidence beyond measures and numbers Lancet 2001; 358: 397-400.

12. Meland E. Gjensidig respekt heller enn omsorgsfull godhet. Tidsskr Nor Lægeforen 2005: 125 : 3442-3.

13. Dyregrov K. Umyndiggjør fagfolk sørgende og kri serammede? Tidsskr Nor Lægeforen 2005; 125 : 1853-5.

14. Strøbech J. Supervision. I: Kaltoft S, Thorgaard L, red. Lægen som lægemiddel. København: Lægeforeningens forlag, 2005: 135-44.

15. Wampold BE. Contextualizing psychotherapy as a healing practice: culture, history, and methods. Applied \& Preventive Psychology 2001; 10: 69-86.

16. Ekeland TJ. Meining som medisin. Ein analyse av placebofenomenet og implikasjonar for terapi og terapeutiske teoriar. Doktoravhandling. Bergen: Universitetet i Bergen, 1999.

17. Balint M. The doctor, his patient and the illness. New York: International Universities Press, 1964.

18. Schei E. Hva er medisin? Oslo: Universitetsforlaget, 2007

19. Schei E. Doctoring as leadership: the power to heal. Perspect Biol Med 2006; 49: 393-406.

20. Thorgaard L. Relationen til patienten. I: Kaltoft S, Thorgaard L, red. Lægen som lægemiddel. København: Lægeforeningens forlag, 2005: 19-33.

21. Gabbard GO, Menninger RW. The psychology of the physician. I: Gabbard GO, Menninger RW, red. Medical marriages. Washington D.C.: American Psychiatric Press, 1988: 23-38.

22. Vetlesen A. Profesjonell og personlig? Legerollen mellom vellykkethet og sårbarhet. Tidsskr Nor Lægeforen 2001; 121: 1118-21.

23. Smith R. Thoughts for new medical students at a new medical school. BMJ 2003; 327: 1430 -3.

24. Aasland OG. Legerollen - fra pidestall til skammel. Tidsskr Nor Lægeforen 2006; 126: 61-2.

Manuskriptet ble mottatt 8.9. 2008 og godkjent 30.4. 2009. Medisinsk redaktør Anne Kveim Lie. 